\title{
A formação dos oostegitos em Porcellio dilatatus Brandt (Crustacea, Isopoda, Oniscidea) em laboratório ${ }^{1}$
}

\author{
Jayme de Loyola e Silva ${ }^{2}$ \\ Maria Aparecida Sídor Coraiola
}

\begin{abstract}
Formation of oostegites in Porcellio dilatatus Brandt (Crustacea, Isopoda, Oniscidea) in laboratory. Woodlice were reared in laboratory in the environmental climate of the city of Curitiba, Brazil, with the purpose of getting to know the process of formation of oostegites. Two kinds of cultivation were adopted: natural populations to be controlled were kept in small glass aquariums resembling the natural environment; and, new-born woodlice were raised each one isolated in small plastic receptacles, with a special diet until two years old or over. When adults, after recognizing their sexes, males and females were put together to copulate during one or more days, and some of the females were fertilized. After 30 days, the fertilized females realized ecdise and acquired oostegites. The complete process (copulation, fecundation, incubation and birth) occurred between 25 and 50 days. The females fertilized only once produced one or more broods, each brood varying from 10 to 30 youngs. The spermatic mass reserved in the seminal receptacle depleted after having realized one, two or, rarely, three broods; the females without sperm in the receptacle realized ecdise, lost oostegites and got again virginal aspect. Females in such condition, kept alone, isolated from males have never acquire oostegites again. Otherwise, in contact with males, once fertilized they realized ecdise and acquired new oostegites. The authors have concluded that the oostegites only are formed because of the received sperm and its continuity depends on the sperm accumulated in the seminal receptacle, for more than one brood.

KEY WORDS. Crustacea, Isopoda, Oniscidea, Porcellio dilatatus, oostegites
\end{abstract}

Porcellio dilatatus Brandt, 1833 é uma espécie de isópodo terrestre menos frequente do que com as quais vive em gregarismo; tem preferência por ambientes úmidos, nas redondezas de moradias, onde encontra também substâncias orgânicas para a sua alimentação. A água dos interstícios da terra adere entre os pleópodos foliares possibilitando a respiração. Durante o dia, devido à insolação, enterram-se e entocados conservam a umidade do corpo. O modo de vida criptozóico, de uma maneira geral, dirigiu os isópodos terrestres a hábitos noturnos.

O marsúpio, por ser um órgão tênue e delicado, também necessita umidade para manter normalmente um grande número de filhotes e para possibilitar o pleno desenvolvimento.

A facilidade de locomoção na terra, a proteção exoesqueletal, o tipo de ecdise, a respiração adaptada aos pleópodos e a possibilidade de conservar a água necessária para o intercâmbio com o meio são alguns fatores de evolução que contribuíram para o sucesso dos isópodos no meio terrestre.

1) Contribuição número 1044 do Departamento de Zoologia, Universidade Federal do Paraná.

2) Departamento de Zoologia, Universidade Federal do Paraná. Caixa Postal 19020, 81531-990 Curitiba, Paraná, Brasil. Bolsista do CNPq. 

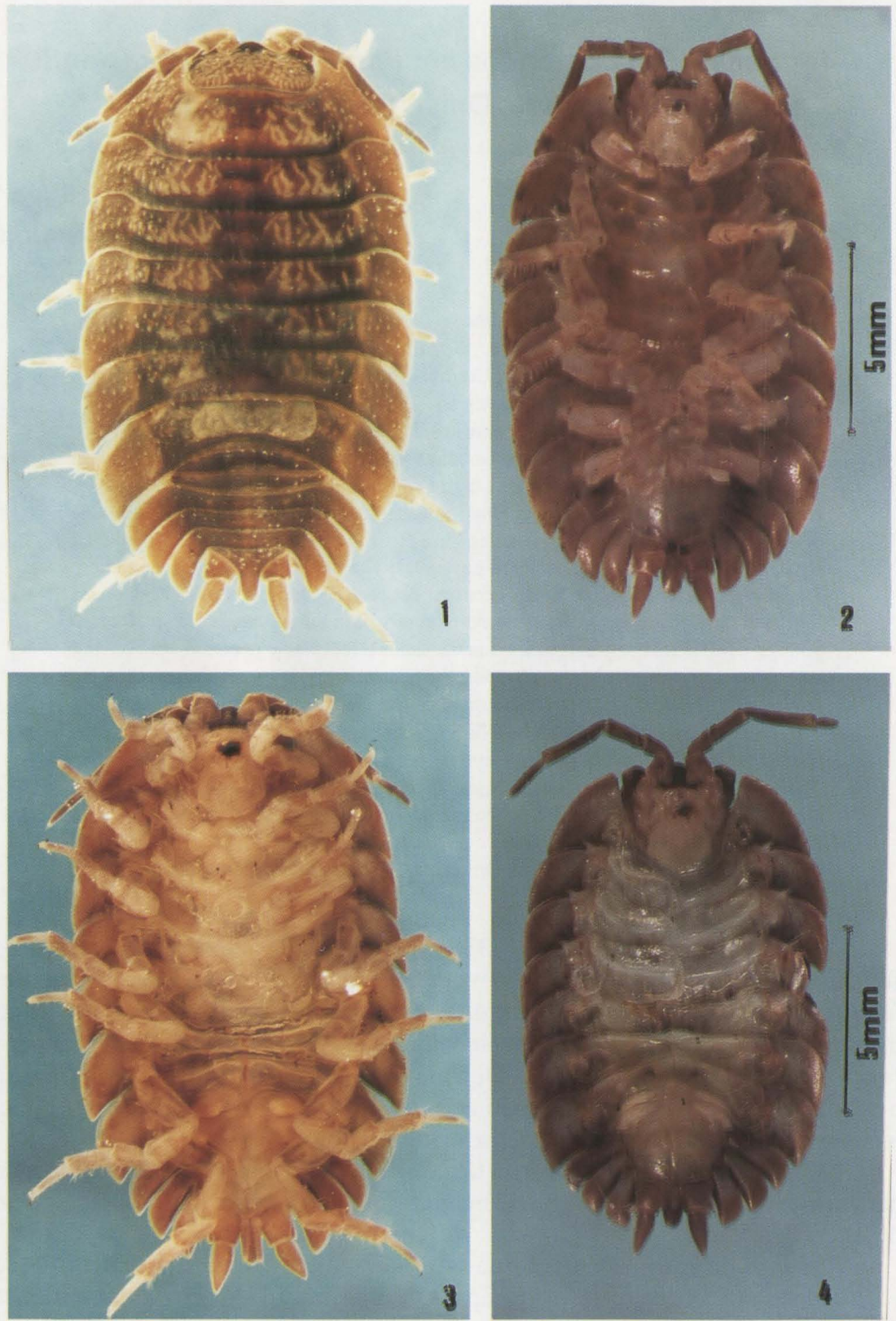

Figs 1-4. Porcellio dilatatus. (1) fêmea adulta, em corpo inteiro, vista dorsal; (2) fêmea ovígera, em corpo inteiro, vista ventral, oostegitos translúcidos deixam transparecer os ovos recém fecundados; (3) fêmea incubadora, em corpo inteiro, vista ventral, os oostegitos translúcidos deixam transparecer embriöes; os olhos, nos filhotes, aparecem como pequenos pontos pretos; (4) fêmea, em corpo inteiro, em vista ventral, removidos os pereópodos a para melhor visão dos oostegitos flácidos, com dobras e sem uniformidade de aderência, indicativo de fêmea logo após ter dado nascimento aos filhotes. 
Além desses fatores, o processo de maior vulto evolutivo foi o evento do marsúpio, estruturado na parte ventral do tórax e formado por pares de oostegitos. Destina-se a abrigar, proteger e permitir o desenvolvimento dos ovos até o estádio de filhotes, então prontos para o nascimento e para a vida independente.

Todos esses aspectos adaptacionais permitiram aos isópodos um alto grau de evolução que se evidencia pela biodiversidade alcançada nos meios terrestres aéreos.

Quando se criam tatuzinhos de jardim, desde o nascimento até a morte, inúmeros e interessantes estudos podem ser feitos, pois o ciclo de vida é realmente fascinante.

As fêmeas adultas podem ser encontradas em dois estádios diferenciados: 1) com a face ventral protegida por esternitos; 2) com a face ventral provida de oostegitos para formar o marsúpio. biológico.

O principal objetivo deste trabalho foi conhecer melhor esse fenômeno

\section{MATERIAL E MÉTODOS}

Porcellio dilatatus Brandt, 1833 (Isopoda, Oniscidea), de nome vulgar "tatuzinho", foi a espécie escolhida para realizar os estudos comportamentais (Fig. $1)$.

As primeiras coletas foram realizadas em 30 de março de 1995, em terrenos baldios, jardins e parques da cidade de Curitiba, sem muito sucesso, pois os ambientes não reuniam boas condições de vida para a espécie.

Terrenos com árvores e arbustos, umidade e restos orgânicos, próximos de residências, constituem ótimos nichos para essa espécie, onde se encontram populações expressivas.

Na natureza, ao levantar um pedaço de madeira ou remover a serapilheira, encontram-se, com facilidade, diferentes espécies de isópodos em gregarismo; quando se vêm a descoberto, com a incidência da luz do dia, embrenham-se e escondem-se o mais rápido, quase sem possibilidade de coleta.

Praticando uma coleta, manual ou com pinças, alguns exemplares serão esmagados ou terão partes do corpo danificadas. Se o interesse é de cultivo deverão ser tomadas certas precauções. Com um pedaço de cartolina, lingüiforme, de $10 \mathrm{x}$ $4 \mathrm{~cm}$, que se manuseia, feito uma pá, coletam-se, sem danificar, muitos exemplares que devem ser passados para um vasilhame com terra do ambiente.

Um dos objetivos que consistia em encontrar fêmeas ovígeras, de $P$. dilatatus, na natureza, no período de março a junho de 1995, não foi alcançado. No criadouro natural, com razoável números de adultos, também não foram encontradas fêmeas ovígeras durante esse período de tempo. Somente a partir de julho, do mesmo ano, apareceram, algumas poucas, fêmeas ovígeras.

As fêmeas adultas, conforme $\mathrm{o}$ aspecto do ventre torácico, apresentam-se em dois estádios diferenciados: com esternitos ou com oostegitos; as com esternitos podem ser virgens ou em fase de repouso reprodutivo. As fêmeas com oostegitos podem ser encontradas em três estádios: fêmeas ovígeras (Fig. 2), quando o 
marsúpio está repleto de ovos; fêmeas incubadoras (Fig. 3), quando o marsúpio está pleno de embriões ou de filhotes e, fêmeas com o marsúpio vazio (Fig. 4), as que acabaram de dar nascimento aos filhotes.

Para o criadouro natural, foi utilizado um aquário de vidro medindo $40 \times 22 \times 24 \mathrm{~cm}$, com terra no fundo, pedaços de madeira apodrecida, pedras, folhas verdes de Nerium oleander (espirradeira) da família Apocynaceae. O ambiente era tampado com vidro e coberto, com flanela, para mantê-lo na penumbra. Os isópodos, em estado adulto, eram criados, em temperatura ambiental para continuação da vida sem muitas modificações em relação ao ambiente natural, com possibilidades de copulação, incubação e nascimento dos filhotes, visando uma população de recém nascidos para o cultivo.

Também foram utilizados para a criação, frascos de $200 \mathrm{ml}$, com diâmetro de $5 \mathrm{~cm}$ por $12 \mathrm{~cm}$ de comprimento. Os frascos foram colocados deitados, em concavidades feitas em placas de isopor, e todos cobertos por cartolina para manter o ambiente escurecido. Cada frasco foi preenchido em $20 \%$ com terra humosa, preta, do próprio local de coleta, que serviu de esteio aos tatuzinhos. Para manter o ambiente com a umidade necessária aos processos vitais do isópodo, foi utilizado um chumaço de algodão embebido em água de torneira, em temperatura ambiente.

$\mathrm{O}$ ambiente de cultivo para recém nascidos, com vistas ao acompanhamento da idade, constituiu-se de um pequeno pote de plástico, leitoso, com capacidade de $35 \mathrm{ml}$; altura de $2,5 \mathrm{~cm}$ por $4,8 \mathrm{~cm}$ de diâmetro e tampa vedando o suficiente para evitar a perda de umidade. O meio para o cultivo constou de folha de papel de filtro a revestir o fundo; de um pouco de terra humosa do mesmo local de coleta; de um chumaço de algodão umedecido em água de torneira; e, como alimento, além da própria terra, folhas verdes, picadas, de espirradeira. Este conjunto ambiental era trocado a cada 15 dias. A criação foi feita ao natural, em temperatura do ambiente da cidade de Curitiba.

Os pareamentos foram feitos a partir do quinto mês, com machos e fềmeas proporcionais em tamanho e em época reprodutiva.

Machos e fêmeas, de tamanho desigual, também foram pareados e várias outras combinações foram feitas. Fêmeas foram deixadas em contato com machos, por um ou mais dias, e depois isoladas.

Os isópodos foram cultivados, isoladamente, desde o nascimento, e acompanhados, em seu crescimento, por mais de dois anos, para comprovação dos dados obtidos com adultos.

Foi utilizado o termo fertilização em virtude do ato copulatório não proporcionar fecundação direta. A massa espermática, recebida pela fêmea, acumula-se no receptáculo seminal e somente depois que os óvulos estiverem aptos, inicia-se a fecundação.

\section{RESULTADOS}

Modos de vida. O tatuzinho de jardim, $P$. dilatatus Brandt, 1833, é uma espécie cosmopolita. Ao natural, em Curitiba, vive em gregarismo, mormente, com Oniscus asellus Linnaeus, 1761, Armadillidium vulgare (Latreille, 1804) e Benthana picta (Brandt, 1833); ocasionalmente, com Porcellionides pruinosus (Brandt, 
1833) e Balloniscus sellowii (Brandt, 1833). Tem modo de vida criptozóico, fazendo galerias subterrâneas, embaixo de pedras, galhos de árvores, detritos de serapilheira e em muitos outros ambientes. As populações de $P$. dilatatus são encontradas, mais comumente, nas proximidades de habitações, atraídas pela facilidade de encontrar restos de alimento.

Quanto a preferência de alimento vegetal foram feitas tentativas com algumas folhas de plantas. Nerium oleander, da família Apocynaceae, comum em Curitiba, conhecida como espirradeira, foi a preferida. Evidente que na falta de folhas verdes os isópodos alimentavam-se também de folhas amareladas mas rejeitavam as partes secas das folhas.

Ecdise. Os jovens nascem com cerca de $2 \mathrm{~mm}$ de comprimento e somente com os seis primeiros pares de pereópodos, faltando o sétimo par. A primeira ecdise, normalmente, realiza-se no primeiro dia de vida.

A muda processa-se em duas fases, ecdise bifásica; exatamente, no meio transverso do animal, entre o quarto e o quinto segmentos do tórax, processa-se a fissão do exoesqueleto. $\mathrm{O}$ isópodo, como que se despindo, libera-se com certo esforço, primeiramente, da exúvia da metade posterior do exoesqueleto do corpo (Fig. 6). Esta região, além do quinto segmento do corpo, fica um pouco maior, o que transparece, em especial, pela ampliação das laterais dos três últimos segmentos do tórax e dos segmentos abdominais. Além disso, a nova cutícula é brilhante, úmida e sem as manchas esbranquiçadas, da cristalização do carbonato de cálcio, existentes na metade anterior do corpo. Enquanto a parte posterior do isópodo, devido a muda, é tênue, a parte anterior continua resistente e os quatro pereópodos anteriores, firmes, podem executar com precisão o deslocamento, para a defesa. No dia seguinte $o$ isópodo libera-se da exúvia da metade anterior do corpo, aquela que fica anteriormente ao quinto segmento do tórax (Fig. 5). O crescimento pode ser notado pela uniformidade de acompanhamento do contorno da região posterior e pela cutícula brilhante, úmida e sem manchas esbranquiçadas.

Durante a ecdise bifásica o isópodo protege-se dos predadores podendo correr com as patas anteriores que guardam a sua firme estrutura, pois as posteriores, devido a troca, encontram-se ainda amolecidas. Quando se inicia a troca da metade anterior do corpo, os três últimos pares de pereópodos, mais ou menos esclerotizados, firmes, possuem agilidade necessária para a locomoção.

As duas exúvias, anterior e posterior (Figs 5-6), de cor branca leitosa, que conservam a forma perfeita do animal, podem servir de alimento ao próprio isópodo, que as devora em poucas horas. Nos indivíduos jovens, nos quais o crescimento é mais acentuado, as ecdises processam-se em menor espaço de tempo; em idade média processam-se mais ou menos de mês a mês, e, em idade adulta mais ou menos de dois em dois meses ou até em espaço de seis meses.

Sempre que o meio de cultivo for adequado para o isópodo, quanto a umidade e alimento, como resultado da ecdise, haverá crescimento. Em meio inadequado, o crescimento poderá ser prejudicado, mesmo que o isópodo realize ecdise poderá não haver crescimento. O maior exemplar cultivado foi uma fêmea com 16,5 mm de comprimento, em estádio de repouso reprodutivo. A maior fêmea ovígera observada nos cultivos, alcançou $15,0 \mathrm{~mm}$. 

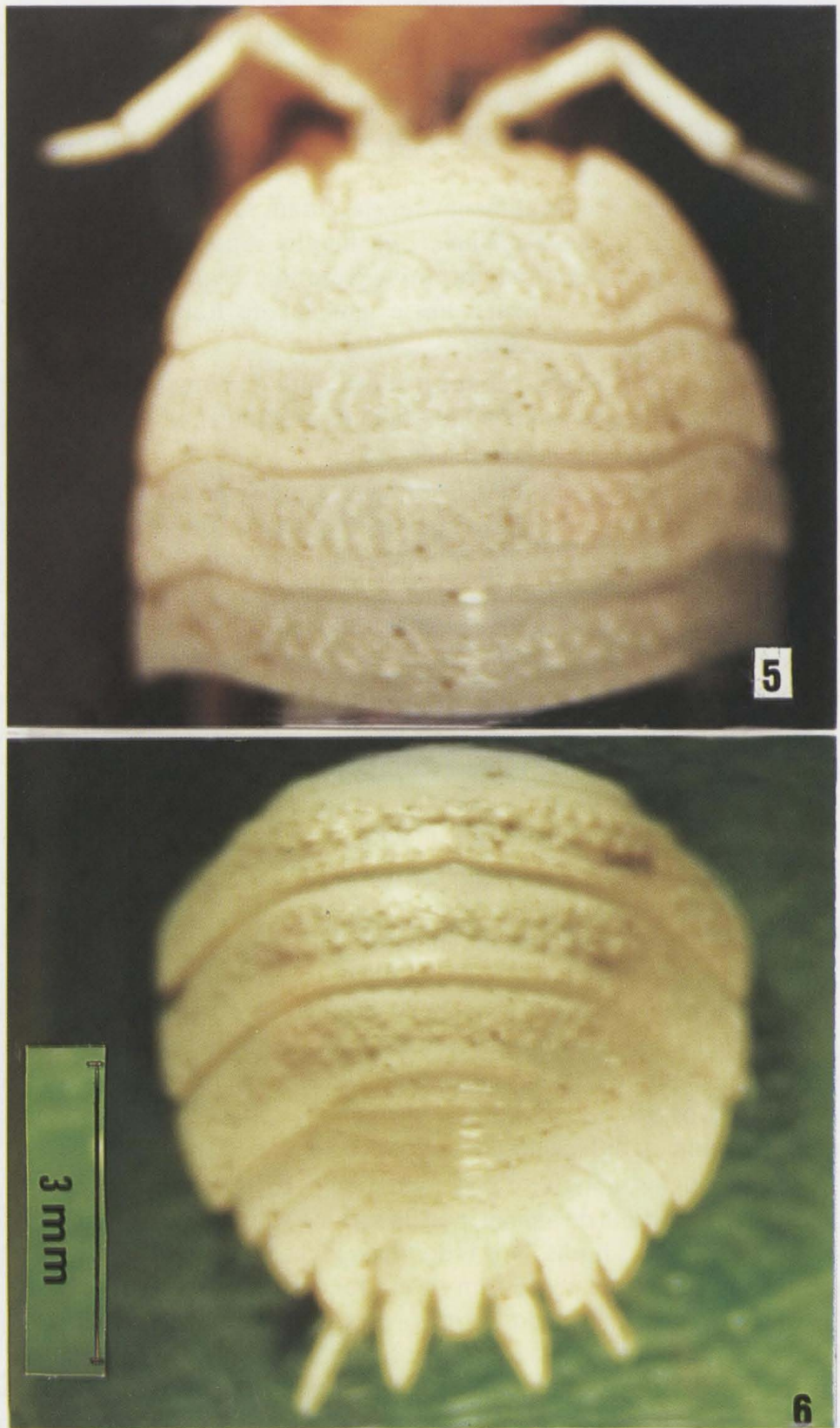

Figs 5-6. Porcellio dilatatus. (5) exúvia da metade anterior do corpo, em vista dorsal, aderente em um ramo vegetal; (6) exúvia da metade posterior do corpo, em vista dorsal, sobre uma folha de Nerium oleander (espirradeira) da familia Apocynaceae. 
Maturidade sexual. As fêmeas mais precoces atingem a maturidade sexual a partir dos quatro meses e meio de idade. A maturidade é relativa; há fêmeas que alcançam esse estádio com cinco meses e meio; os exemplares com essa idade alcançam o comprimento de cerca de $5 \mathrm{~mm}$.

Época reprodutiva. Varia de acordo com o clima de cada região. Uma espécie pode ter épocas reprodutivas diferentes, de um local para o outro, até em uma mesma região (VANDEL 1925).

Durante as inúmeras coletas realizadas, em Curitiba, entre os meses de março e junho e nos cultivos de populações naturais jamais foram encontradas fêmeas grávidas. Foram pareados machos e fêmeas, em idade adulta, nessa mesma época do ano, e não houve fertilização. Infere-se que este período seja de infertilidade para $P$. dilatatus, na cidade de Curitiba. Nas fêmeas cultivadas em laboratório o período de infertilidade estende-se um pouco mais, de março a julho.

A época reprodutiva em Curitiba, iniciou-se com poucas fêmeas ovígeras, no mês de julho e estendeu-se até fevereiro. Evidente, que não se pode confirmar esse período reprodutivo para o Estado do Paraná, nem mesmo para a cidade de Curitiba, pois a variação ambiental é grande.

Copulação. A probabilidade de observar o ato copulatório é muito pequena pois realiza-se em período noturno e processa-se rapidamente.

Fertilização. $\mathrm{O}$ termo fertilização foi o preferido pois não há fecundação no momento da cópula. A massa espermática recebida pela fêmea é armazenada no receptáculo seminal.

Os óvulos procedentes dos dois ovários começam a transitar, passando, um a um, pela conjunção ovário, receptáculo seminal e oviduto onde se realiza a fecundação. Os ovos deslizam pelo oviduto até o marsúpio, onde se alojam. Os oostegitos amoldam-se para conter o maior número de ovos; estes começam o desenvolvimento e dentro do marsúpio atingem o estádio de embriões, seguindo-se o desenvolvimento em vários graus. O marsúpio torna-se avolumado; as placas de incubação expandem-se ao máximo, formando uma grande protuberância no ventre do corpo para conter os filhotes, apinhados, uns em cima dos outros, prontos para o nascimento.

Esse tipo de reprodução, constitui-se num processo adaptacional evolutivo, pois surge o receptáculo seminal como importante órgão armazenador de esperma, auxiliar da fecundação e proporcionador de mais de uma ninhada, independente de novas fertilizações.

Uma fêmea grávida, com o marsúpio repleto de ovos (Fig. 2), foi separada da população natural, cultivada isoladamente e depois de um mês nasceram os filhotes. Em seguida a fêmea realizou ecdise e adquiriu, novamente, esternitos, tomando o aspecto virginal. Durante quatro meses foi mantida isolada do contato com machos; teve ecdises normais sem que houvesse readquirido oostegitos. Em seguida foi acasalada, houve copulação e antes de um mês realizou ecdise e apareceram oostegitos. Seguiu-se, normalmente, o processo reprodutivo com o nascimento dos filhotes depois de 44 dias. Em seguida a fêmea realizou nova ecdise mas desta vez vingaram os oostegitos. E, sem que houvesse nova fertilização, pois 
a fêmea foi mantida em isolamento, houve a segunda fecundação, depois de 16 dias; o processo de incubação dos ovos, filhotes e nascimento deu-se normalmente. Isso significa que a quantidade de esperma recebida pela fêmea, numa única cópula, não havia sido totalmente despendida com a fecundação anterior.

Convém salientar que o cultivo de uma espécie de isópodo, em população natural, com os indivíduos devidamente marcados, mas todos juntos, não permite precisar os processos de formação dos oostegitos e a sua dependência do líquido espermático.

Oostegitos. Em determinadas épocas do ano, encontram-se fêmeas adultas de $P$. dilatatus em dois estádios diferenciados quanto ao revestimento da face ventral. Em algumas fêmeas esta face é protegida por esternitos, iguais aos dos machos, fusionados nas linhas transversal e sagital, calcificados mas levemente articuláveis. Em outras, em processo de reprodução, a face ventral encontra-se revestida por cinco pares de oostegitos que constituem o marsúpio.

Os cinco pares de oostegitos originam-se nas partes internas das inserções dos cinco primeiros pares de pereópodos. Cada oostegito constitui-se de uma lâmina quitinosa fina e tênue, com certa resistência devido a parte central, raquis, mais consistente; as lâminas são alargadas ântero-posteriormente, alongadas além da linha média e colocam-se, imbricadamente, tanto na posição ântero-posterior como na parte mediana. A imbricação das lâminas permite a expansão e o amoldamento para conter o maior número de filhotes.

A região ventral da fêmea grávida, onde havia esternitos, torna-se a porção dorsal ou superior do marsúpio; dessa porção, centralmente, pendem hilos, um em cada segmento, produtores da mucosidade que lubrifica os embriões protegendo-os do atrito e garantindo a umidade necessária ao desenvolvimento.

O marsúpio recém formado é vazio, apresenta os oostegitos mais ou menos tênues, bem justapostos, e aderentes ao ventre; a fêmea, nesse estado, apresenta o exoesqueleto ainda brilhante, mais ou menos mole, resultado da ecdise recente.

O marsúpio esgotado também é vazio; os oostegitos são flácidos, com dobras, sem uniformidade de aderência (Fig. 4); o exoesqueleto, da fêmea nesse estado, é endurecido, marrom escuro, com manchas esbranquiçadas devido a calcificação.

Conforme o tempo de formação, o marsúpio conterá ovos ou embriões em vários graus de desenvolvimento. Os embriões, no marsúpio, ficam protegidos das adversidades do meio; empilham-se uns sobre os outros mas podem ser, facilmente, percebidos através da translucidez dos oostegitos (Fig. 3).

As lâminas oostegitos também são lubrificadas e mantêm-se úmidas permitindo a boa aderência e a grande plasticidade o que as torna um perfeito órgão de proteção à prole. Os primeiros filhotes, para nascer, forçam a imbricação ânteroposterior entre o primeiro e segundo pares de oostegitos, deixando uma fenda, por onde todos os outros deixam o marsúpio.

Recém nascidos. Os jovens assemelham-se aos adultos mas possuem somente seis pares de pereópodos; falta o sétimo. Esse estágio, que dura poucos dias, denomina-se manca. 
Os jovens manca, vivem independentemente, alimentando-se e locomovendo-se com perfeição. Num jovem manca de 14 dias de idade os dois pereópodos do sétimo par, bem formados, são visíveis através da cutícula, colocados em paralelo, em sentido transverso ao corpo, como dois braços cruzados. A ecdise que se processa, logo a seguir, ao liberar a exúvia posterior deixa à vista o sétimo par de patas ainda aderente à parte ventral do corpo, colocado em paralelo transverso. Aos poucos, os dois pereópodos que compõem o sétimo par, vão se distendendo, mas são muito menores e mais tênues que qualquer dos pereópodos anteriores. A cada ecdise crescem, e quando o animal atinge o estado adulto constituem-se no maior par de pereópodos, chegando a medir uma vez e um quarto o comprimento do primeiro par.

Formação dos oostegitos e esternitos. Os acasalamentos entre machos e fêmeas foram feitos, com várias combinações, para o entendimento do processo de formação dos oostegitos que: 1) se formam somente em fêmeas fertilizadas; 2) não são perenes; 3 ) podem ser formados mais de uma vez por ano; 4) são substituídos por esternitos quando se esgota o líquido espermático do receptáculo seminal da fêmea.

Inúmeros indivíduos recém nascidos foram cultivados, isoladamente, cada um, num nicho especial, por mais de dois anos. Durante o desenvolvimento, permitiram conhecer a idade exata, o sexo, a linhagem pura e a certeza de que as fêmeas jamais tiveram contato com machos.

Os caracteres dimórficos secundários dos pleópodos apareceram somente depois de 80 dias de idade e as fêmeas continuaram sendo cultivadas até mais de dois anos. Como normalmente, durante toda a vida, as fêmeas realizaram várias ecdises para o crescimento, persistiram os esternitos e jamais, em momento algum, se formaram os oostegitos que deveriam constituir o marsúpio.

Algumas fêmeas, dessa linhagem pura, sexualmente adultas, foram pareadas durante um ou mais dias, com machos escolhidos e nas mesmas condições, quanto à idade e tamanho; o casal foi criado, em nicho ambiental especial, em época reprodutiva e houve fertilização. Em seguida, depois desse período de pareamento, as fêmeas foram conservadas isoladas dos machos e no espaço de 20 a 30 dias sofreram ecdise e adquiriram oostegitos.

O processo de ovulação, fecundação, incubação e nascimento ocorreu, entre diversas fêmeas, num espaço que variou entre 25 e 50 dias. Entre 15 a 30 dias, após o nascimento da primeira ninhada, algumas fêmeas sofreram nova ecdise, perderam os oostegitos e readquiriram esternitos.

Outras fêmeas, com a mesma combinação de acasalamento, depois da copulação, foram mantidas isoladas dos machos e tiveram uma segunda ninhada, no mesmo marsúpio, o que ocorreu cerca de 11 dias após o nascimento dos primeiros filhotes; em outras após 16 dias. Raramente, ocorreu a persistência de um mesmo marsúpio para mais de duas ninhadas.

Entre uma ninhada e outra poderá haver ecdise e a repetição da formação de novos oostegitos; esse fenômeno acontece porque o receptáculo seminal, por ocasião da cópula, recebe uma quantidade maior de esperma que permite a continuidade do marsúpio para conter uma ou mais ninhadas. 
Dependendo da ejaculação o receptáculo seminal acumulará maior ou menor quantidade de esperma. Houve fêmeas que, logo após a primeira ninhada, sofreram ecdise, perderam o marsúpio e readquiriram esternitos. Esse fenômeno aconteceu porque, o receptáculo seminal estava esgotado, não havia mais esperma.

Todas as fêmeas, depois do pareamento, foram isoladas do contato com machos, algumas por tempo determinado, outras para o resto da vida. As que ficaram isoladas por tempo determinado e acasaladas pela segunda vez adquiriram, novamente, oostegitos. As que ficaram isoladas perenemente do contato com machos, jamais formaram oostegitos.

Macho e fêmea, com três meses de idade, distintos pelos caracteres sexuais dos pleópodos, foram acasalados, em época reprodutiva e a fertilização efetivou-se somente após a idade de cinco e meio meses. Este tipo de acasalamento poderia sugerir a maturação dos machos mais tardia que a das fêmeas.

Novas combinações foram idealizadas. Fêmea de 2 meses e 21 dias, já apresentando os caracteres sexuais secundários, foi pareada com macho de 4 meses e 16 dias. A fêmea adquiriu oostegitos somente ao completar 6 meses e 25 dias e foi, imediatamente, separada do macho. Deu-se, normalmente, o nascimento dos filhotes e processou-se uma segunda ninhada sem que houvesse ecdise. Em seguida, a fềmea após ecdise perdeu os oostegitos e readquiriu esternitos. Essa combinação mostra que fềmeas com cerca de 80 dias, com caracteres dimórficos evidentes, ainda não estão maduras e que uma fertilização é o suficiente para mais de uma ninhada.

Das inúmeras combinações de acasalamentos sabemos que o marsúpio se forma em fêmeas recém fecundadas e permanece determinado tempo, às vezes por mais de uma ninhada, na dependência da quantidade de esperma recebido e acumulado no receptáculo seminal. Pouco esperma determina uma única ninhada e logo a seguir ecdise com retorno da fêmea ao estagio virginal, com esternitos no ventre. Os cinco pares de oostegitos que formam o marsúpio, são frágeis, lubrificados e bem aderentes uns aos outros, para não permitir intrusos; suficientemente fortes para sustentar a prole; permitem a oxigenação e a confortabilidade para os filhotes, cerca de 30, que se colocam, apinhadamente, no interior marsupial (Fig. 3). Nessa fase a fêmea incubadora torna-se mais vulnerável ao ataque de organismos estranhos, mas protege-se entocada, escondida e com pouca movimentação. Depois do nascimento dos filhotes, caso não haja outra incubação, as lâminas oostegitos ficam flácidas (Fig. 4) e desprotegidas possibilitando o ataque de organismos estranhos. Processa-se, então, de imediato, uma ecdise e os oostegitos são substituídos por esternitos. Os esternitos, mais fortes e resistentes que os oostegitos, protegem a parte ventral da fêmea durante a fase de repouso.

O período de repouso destina-se ao descanso das fêmeas que, depois de uma ou mais ninhadas, encontram-se extenuadas devido ao processo reprodutivo.

As fêmeas adultas, fertilizadas, apresentam oostegitos, por tempo determinado, e depois esternitos. O marsúpio não é um órgão perene que se forma em fêmeas maduras e fica a espera de ovos para a incubação. O marsúpio é um órgão temporário que se forma somente em fềmeas fertilizadas. A sua continuidade, por determinado tempo, para mais de uma ninhada, está na dependência da quantidade de esperma recebido e acumulado no receptáculo seminal. 


\section{Sinopse da biologia reprodutiva}

Determinação do sexo ........................ a partir de 80 dias Maturidade sexual da fêmea ................... entre 135 a 165 dias Aparecimento dos oostegitos após a fertilização ............ de 20 a 30 dias Ovulação, fecundação, incubação e nascimento ........... de 25 a 50 dias Do nascimento à segunda ninhada no mesmo marsúpio ....... a partir de 11 dias Número de incubações num mesmo marsúpio ................. de 1 a 3 Número de filhotes por ninhada ..................... de 10 a 30

\section{DISCUSSÃO}

VANDEL (1925) diz: “a mais notável característica de uma muda de isópodo é aquela que se faz em dois tempos, separados por um intervalo de vários dias". O autor quando se refere a intervalo de vários dias, o faz de uma maneira generalizada, e não incisivamente sobre uma espécie. Em $P$. dilatatus, espécie objeto do estudo realizado, a muda bifásica processa-se de um dia para o outro. Num dia o isópodo libera-se da exúvia posterior e no dia seguinte da anterior.

$\mathrm{O}$ autor acima citado afirma que o desenvolvimento dos oostegitos é independente da fecundação. Com a espécie trabalhada os resultados foram diferentes. As várias combinações de acasalamento permitiram afirmar que as fêmeas adquiriram oostegitos somente depois de terem sido fertilizadas. Vários indivíduos, recém nascidos, independentemente do reconhecimento do sexo, foram criados, isoladamente, até mais de dois anos e as fêmeas jamais formaram os oostegitos.

HEELEY (1941) estudando $P$. dilatatus na Inglaterra, afirma que o período embriônico, que ocorre no marsúpio, foi no máximo de 79 dias e no mínimo de 27 dias. As pesquisas realizadas, com a mesma espécie, mostraram uma variação de 30 a 50 dias. Entende-se esta diferença face aos ambientes diversos.

Ainda, segundo este autor, o período de liberação entre a primeira e a segunda ninhadas corresponde no máximo a 109 dias e no mínimo a 48 dias. Os estudos realizados, atualmente, mostraram uma variação entre 30 a 60 dias.

Diz ainda que o esperma recebido permanece vivo no oviduto por longo tempo, com o que concordamos plenamente.

Pensa, também, o autor acima referido, que o esperma seria suficiente para duas ninhadas, uma em cada ano, uma vez que manteve fêmeas isoladas sem possibilidades de pareamento. Quanto a esse aspecto, os resultados que obtivemos foram diferentes; as fêmeas fertilizadas uma única vez podem produzir até três ninhadas sucessivas, no mesmo ano, desde que possuam esperma no receptáculo seminal.

A respeito da ecdise nos isópodos diz o autor acima referido que a muda do exoesqueleto em dois estágios dá-se em dois ou três dias. $\mathrm{Em} P$. dilatatus, estudado em Curitiba, as ecdises processam-se de um dia para o outro, ou até no mesmo dia, dependendo da idade do animal. As ecdises processadas em menor tempo, possivelmente, ocorrem em razão da influência do meio. 
ARCANGELI (1943) diz, de uma maneira geral, que nos isópodos terrestres as fêmeas são fertilizadas uma única vez ao ano e que a copulação serve para várias ninhadas. Esta afirmativa é baseada no modo pelo qual o exoesqueleto é lançado nas sucessivas ninhadas e na formação dos oostegitos para cada ninhada. Os trabalhos por nós realizados incidiram sobre uma única espécie, $P$. dilatatus, e não se pode generalizar as conclusões para todos os isópodos terrestres e muito menos ampliar para todo o mundo. As conclusões, estabelecidas, no presente trabalho, diferem das de Arcangeli, em quase todos os pontos: uma fêmea que tenha atingido a maturidade sexual poderá ser fertilizada mais de uma vez por ano; nem sempre uma copulação serve para várias ninhadas mas às vezes para uma única; uma fêmea pode dar nascimento para mais de uma ninhada sem que haja troca do exoesqueleto; nem sempre há formação de oostegitos novos para cada ninhada; os mesmos oostegitos podem ser reutilizados para mais de uma ninhada.

COLLINGE (1945) diz que um dos preparos iniciais para a ecdise é a produção de um líquido viscoso, entre a velha e a nova cutícula, destinado a facilitar a muda e evitar danos. As nossas observações concordam totalmente com este autor, pois logo após uma ecdise a cutícula nova é brilhante e apresenta viscosidade. Diz ainda que as exúvias se colam às lâminas de vidro. Das várias exúvias guardadas, algumas ficaram coladas às folhas ou ramos de vegetais.

COLLINGE (1946) apresenta um estudo sobre a longevidade de vida de várias espécies de isópodos terrestres. Estimou para Porcellio dilatatus a duração máxima de vida de 3 anos, 5 meses e 25 dias. Como o cultivo mantido durou um pouco mais de dois anos, tempo suficiente para concluir os estudos, não foi possível estimar a longevidade da espécie.

LOYOLA E SILVA (1959) utilizou o método do cultivo isolado; apresentou inúmeras combinações entre machos e fêmeas. Muitas conclusões coincidem com as apresentadas no presente trabalho.

NAIR (1976) trabalhando com Porcellio laevis (Latreille, 1804) da região de Delhi, Índia, diz que a espécie não apresenta muita seletividade a respeito do alimento; alimenta-se, mormente, de matéria orgânica morta como folhas caídas e cascas de árvores; que os testes mostraram que a espécie tem preferência por folhas mortas de Morus indica quando tem disponibilidade de escolha. A espécie de isópodo, referencial para os trabalhos desenvolvidos, prefere, entre outras, as folhas de Nerium oleander (espirradeira), tenras, verdes, recém colhidas da árvore. Evidente que na falta destas alimenta-se também de folhas amareladas mas rejeita as partes secas das folhas.

No que se refere às atividades reprodutivas NAIR (1976) diz que a produção de ovos começa em fevereiro e continua até outubro. Como se trata de outra espécie e de região diferente não se poderia esperar coincidência entre os dados biológicos.

HADDAD (1982) usou para cultivo de Balloniscus sellowii (Brandt, 1833) folhas de Nerium oleander, em decomposição, com que obteve melhores resultados. Das pesquisas realizadas com $P$. dilatatus, o melhor resultado foi obtido com folhas tenras e verdes recém colhidas da árvore. 
OLIVER \& MEECHAN (1993) constataram que, para as espécies de isópodos da Inglaterra, o número de embriões varia de quatro ou cinco para espécies de menor tamanho até oitenta para as maiores. Em nosso meio $P$. dilatatus e $A$. vulgare assemelham-se em tamanho; enquanto a primeira espécie apresenta cerca de 30 filhotes numa ninhada, a segunda pode apresentar até 80 filhotes.

Estes autores dizem, também, que o número de ninhadas depende da espécie e do clima onde vive. E generalizam afirmando que para a maioria das espécies de isópodos terrestres há apenas uma ninhada por ano. Fazem exceção, citando outros autores, $P$. muscorum que produz duas ninhadas por ano e $P$. laevis, do leste do Mediterrâneo, de quatro a seis ninhadas por ano. Com a espécie $P$. dilatatus, cultivada em laboratório, num nicho o mais natural possível, as fêmeas podem ter, normalmente, uma ou duas ninhadas por ano, dependendo da quantidade de esperma recebida e armazenada no receptáculo seminal.

Ainda, segundo os autores antes mencionados, a espécie $P$. dilatatus é estenohigra, prefere lugares úmidos, não vingando em locais secos. Concorda-se, plenamente, pois os cultivos foram umedecidos, praticamente todos os dias, para evitar mortandade em caso de ressecamento do ambiente. Ao natural, em terrenos com árvores, arbustos, umidade e restos orgânicos, encontram-se populações expressivas, o que não acontece em locais descampados de ambientes mais secos.

\section{CONCLUSÕES}

O aparecimento dos caracteres sexuais secundários, dimórficos, em Porcellio dilatatus Brandt, 1833, dá-se a partir de 80 dias de idade em Curitiba, Paraná, Brasil.

A maturidade sexual varia desde 135 até 165 dias de idade.

As ecdises processam-se bifasicamente, de um dia para o outro.

O marsúpio é um órgão temporário que se forma somente em fêmeas fertilizadas.

A continuidade do marsúpio, para mais de uma ninhada, sem sofrer ecdise, depende do esperma acumulado no receptáculo seminal.

Fêmeas criadas isoladas de machos jamais formaram oostegitos por nunca terem recebido esperma.

Os processos reprodutivos de ovulação, fecundação, incubação e nascimento acontecem entre 25 e 50 dias.

O número de filhotes varia de 10 a 30 por ninhada.

Após uma ninhada, a fêmea sofre ecdise, perde os oostegitos e adquire esternitos, somente se não houver mais reserva de esperma no receptáculo seminal.

De uma ninhada para outra pode ocorrer ecdise mas se houver esperma no receptáculo seminal a fêmea readquire oostegitos. 


\section{REFERÊNCIAS BIBLIOGRÁFICAS}

ARCANGELI, A. 1943. Appunti sulla reproduzione degli Isopodi terrestri (crostacei).

Boll. Ist. Mus. Zool. Torino 1 (1): 5-13.

Collinge, W.E. 1945. On the Ecdysial Fluid in Terrestrial Isopoda. Ann. Mag.

Nat. Hist., ser. 11, 12: 139-140.

1946. The Duration of Life in Terrestrial Isopoda. Ann. Mag. Nat. Hist., ser. 11, 13: 719-720.

HADDAD, M.A. 1982. Estádios do desenvolvimento pósmarsupial de Balloniscus sellowii (Brandt, 1833) (Isopoda, Oniscoidea). Dusenia, Curitiba, 13 (3): 135143.

HEELEY, W. 1941 Observations on the Life-Histories of some Terrestrial Isopods. Proc. Zool. Soc. London., ser. B., 111: 79-149.

LoYola E Silva, J. DE. 1959. Sobre a formação das placas de incubação e sua continuidade na dependência do líquido espermático em Porcellio sp. (Isopoda, Crustacea). Forma et Functio, Curitiba, 1 (7): 79-86.

NAIR, G.A. 1976. Food and reproduction of the soil isopod, Porcellio laevis. Int. Jour. Ecol. Environ. Sci. 2: 7-13.

Oliver, P.G. \& C.J. MeECHAN. 1993. Woodlice. Synop. Brit. Fauna. 49: 1-17.

VANDEL, A. 1925. Recherches sur la sexualité des Isopodes. Les conditions naturelles de la reproduction ches les Isopodes terrestres. Bull. Biol. Fr. Belg. 59 (3): 317-371.

Recebido em 19.II.1998; aceito em 23.VI.1999. 